\title{
A COMPLEXIDADE DA PROTEÇÃO DE DADOS
}

\section{Marion Albers}

Professora de Direito Público, Direito da Informação e da Comunicação, Direito da Saúde e Teoria do Direito da Universidade de Hamburgo. E-mail: <marion.albers@jura. uni-hamburg.de>.

\begin{abstract}
Resumo: O presente artigo propõe a tese de que a proteção de dados é, por natureza, uma área extraordinariamente complexa e exige, por isso, uma regulamentação complexa e de múltiplos níveis. A moderna proteção de dados requer novas abordagens jurídicas, e o artigo oferece uma análise teórica e jurídica levando em conta o direito alemão e europeu. A hipótese é de que os padrões de pensamento elementares precisam ser construídos de maneira diferente para se alcançar uma legislação adequada de proteção de dados, tendo em vista: (i) a complexidade do assunto - sob o ponto de vista dos dados, informações, conhecimento e fluxo de dados e informações, decisões e respectivas consequências; (ii) a complexidade dos interesses protegidos dos indivíduos afetados; e (iii) a complexidade dos conceitos apropriados para a regulamentação.
\end{abstract}

Palavras-chave: Proteção de dados pessoais. Privacidade. Direito europeu.

Sumário: 1 Introdução - 2 Paradigmas norteadores da proteção de dados com base nos direitos fundamentais - 3 A complexidade da proteção de dados: análises e consequências - 4 Olhando para frente: o direito referente à proteção de dados como nova área central do direito

\section{Introdução}

Falar da complexidade da proteção de dados parece um pouco irritante. Não seria uma abordagem melhor estabelecer alguns princípios simples que oferecessem orientação jurídica para o processamento de dados pessoais? Em contraposição a esse pensamento, o presente artigo propõe a tese de que a proteção de dados é, por natureza, uma área extraordinariamente complexa e exige, por isso, uma regulamentação complexa e de múltiplos níveis. A moderna proteção de dados requer novas abordagens jurídicas.

Este artigo oferece uma análise teórica e jurídica levando em conta o direito alemão e europeu. Na Alemanha, o direito referente à proteção de dados se desenvolveu bastante cedo e foi refinado a ponto de se tornar um amplo complexo de normas que trata de direitos fundamentais e de regras jurídicas. Por um lado, a legislação sobre a proteção de dados na Alemanha é, entrementes, parcialmente 
determinada pela legislação europeia, especialmente no que diz respeito ao Regulamento Europeu da Proteção de Dados, que entrará em vigor a partir de 2018. Por outro lado, há um impacto sobre a legislação europeia que decorre da influência recíproca na legiferação e da rede jurisdicional existente entre o Tribunal Constitucional Federal alemão, a Corte Europeia de Direitos Humanos e o Tribunal de Justiça Europeu.

A análise começa apresentando a concepção de direitos fundamentais que influencia a proteção de dados de modo significativo (seção 2.1). Além do direito à privacidade, o direito à autodeterminação informacional tornou-se um princípio norteador para descrever os interesses tutelados, especialmente no ordenamento jurídico alemão (seção 2.2). Os conceitos de direitos fundamentais influenciam as abordagens, princípios e construtos jurídicos da legislação de proteção de dados em alto grau (seção 2.3). Minha hipótese é de que os padrões de pensamento elementares precisam ser construídos de maneira diferente para se alcançar uma legislação adequada de proteção de dados. Então se mostrará que a proteção de dados é uma área altamente complexa e nova, que implica desafios particulares para o direito. Essa hipótese será explicada na seção 3, levando em conta três aspectos: em primeiro lugar, o objeto da proteção de dados é complexo, a saber, não apenas dados pessoais, mas uma rede que consiste de vários elementos básicos: dados e informações, conhecimento e o fluxo de dados e informações, decisões e as consequências delas (seção 3.1). Em segundo lugar, a proteção de dados não pode ser reduzida a um bem juridicamente tutelado de modo uniforme. Ela compreende um conjunto complexo de interesses e posições jurídicas que visam proteger o indivíduo em sua socialidade (seção 3.2). Em terceiro lugar, a proteção de dados exige conceitos complexos de regulamentação que precisam não só articular de maneira apropriada o direito relativo à proteção de dados com as normas legais substantivas concernentes à questão, mas também integrar elementos básicos da regulamentação de riscos ou da legislação sobre tecnologia (seção 3.3). Afinal de contas, o direito referente à proteção de dados é tudo, menos burocrático. Ele é moderno e empolgante, exigindo, ao mesmo tempo, um aperfeiçoamento em muitos sentidos.

\section{Paradigmas norteadores da proteção de dados com base nos direitos fundamentais}

O conceito de proteção de dados surgiu na década de 1970 sobre o pano de fundo dos sistemas de computação do tipo mainframe. Os primeiros conjuntos de 
regras jurídicas foram desenvolvidos em nível europeu, bem como na Alemanha. ${ }^{1}$ Tendo em vista que enormes quantidades de dados estavam sendo processados nesses sistemas em uma sequência predefinida, pensou-se que os diversos passos do processamento de dados, incluindo sua coleta, o armazenamento e o uso de dados, teriam de ser controlados. A atenção se concentrou na regulamentação dos diversos passos do processamento de dados. ${ }^{2}$

Esse pano de fundo e os padrões de pensamento a ele associados formaram a base não só para as primeiras regras de proteção de dados, mas também para a substância dos direitos fundamentais que foram concretizados ou desenvolvidos em reação aos desafios implicados no processamento eletrônico de dados pessoais. A partir dos anos 1970, o direito à privacidade começou a ser interpretado de uma maneira nova. ${ }^{3} \mathrm{Na}$ Alemanha, o Tribunal Constitucional Federal derivou o direito à autodeterminação informacional em sua decisão sobre o censo populacional tomada em 1983. ${ }^{4}$ Mais tarde, os direitos fundamentais se tornaram rapidamente os princípios norteadores para a compreensão geral da proteção de dados pela legislação.

Os direitos fundamentais, por sua vez, estão associados a certos padrões de observação e pensamento. A compreensão tradicional dos direitos fundamentais está vinculada a paradigmas liberais. De acordo com essa noção, eles têm a ver com a proteção contra violações ou ingerências por parte do Estado. Embora atualmente ampliações das funções dos direitos fundamentais - por exemplo, direitos à proteção por parte do Estado ou garantias institucionais - sejam reconhecidas em princípio, a proteção contra violações ou ingerências é muitas vezes considerada a dimensão primordial de tutela nos direitos fundamentais; ela ainda é a abordagem predominante. Entretanto, essa abordagem tem pré-requisitos e limitações que influenciam a substância e as funções que os direitos fundamentais podem ter.

1 Cf. a Convenção no 108 sobre a Proteção de Indivíduos com Respeito ao Processamento Automático de Dados Pessoais de 28 de janeiro de 1981; MAYER-SCHÖNBERGER, Viktor. Generational Development of Data Protection in Europe. In: AGRE, Philip E.; ROTENBERG, Marc (ed.). Technology and Privacy. The New Landscape. Cambridge: MIT Press, 1997, p. 219, 220 ss.; BYGRAVE, Lee A. Data Protection Law. The Hague: Kluwer, 2002, p. 94 ss. A respeito da modernização, cf. <http://www.coe.int/en/web/portal/28january-data-protection-day-factsheet>. Cf. também NOUWT, Sjaak. Towards a Common European Approach to Data Protection: A Critical Analysis of Data Protection Perspectives of the Council of Europe and the European Union. In: GUTWIRTH, Serge et al. (Ed.). Reinventing Data Protection? Dordrecht: Springer, 2009, p. 275, 286 ss. Quanto ao histórico da proteção de dados na Alemanha, cf. ABEL, Ralf-Bernd. Geschichte des Datenschutzrechts. In: ROSSNAGEL, Alexander (ed.). Handbuch Datenschutzrecht. München: Beck, 2003, cap. 2.7. n. 1 ss.

2 A seguinte obra foi influente na Alemanha: STEINMÜLLER, Wilhelm; LUTTERBECK, Bernd; MALLMANN, Christoph; HARBORT, Uwe; KOLB, Gerhard; SCHNEIDER, Jochen. Grundfragen des Datenschutzes: Gutachten im Auftrag des Bundesministeriums des Innern, 1971. BTDrucks. VI/3826, Apêndice 1.

3 Cf., entre outros, WESTIN, Alan. Privacy and Freedom. 6. ed. New York: Atheneum, 1970, p. 42.

4 BVerfGE 65, 1, 42 ss.; 15 dez. 1983, sentença sobre o Censo. 
O direito à autodeterminação informacional derivado pelo Tribunal Constitucional Federal alemão serve para ilustrar isso muito claramente. Na seção seguinte, o conceito tradicional de direitos fundamentais e suas limitações serão elucidados, bem como as características do direito à autodeterminação informacional e seu impacto sobre o direito relativo à proteção de dados.

\subsection{0 conceito tradicional de direitos fundamentais \\ 2.1.1 Proteção contra violações ou ingerências como padrão central dos direitos fundamentais}

Segundo a concepção "clássica" baseada no liberalismo, os direitos fundamentais servem primordialmente como direitos protetivos do indivíduo contra intervenções por parte do Estado. ${ }^{5}$ As pessoas protegidas desfrutam de certas liberdades ou posições legais. Medidas estatais que interfiram nessas liberdades podem ser prevenidas por meio de recursos jurídicos, contanto que não estejam previstas no direito constitucional.

A concepção tradicional de proteção contra violações ou ingerências como padrão central dos direitos fundamentais se reflete de modo mais ou menos claro em sua codificação, por exemplo na Convenção Europeia dos Direitos Humanos (CEDH), na Carta dos Direitos Fundamentais da União Europeia (Carta) ou na Lei Fundamental alemã (GG [Grundgesetz], na sigla em alemão). A jurisprudência da Corte Europeia de Direitos Humanos, do Tribunal de Justiça Europeu e do Tribunal Constitucional Federal alemão elaborou a função dos direitos fundamentais na tutela contra violação ou ingerência em numerosas decisões.

Em termos de sua estrutura, os direitos fundamentais implicam, por um lado, o escopo da proteção e, por outro, a reserva que permite uma regulamentação legal, contanto que essa regulamentação cumpra todas as exigências constitucionais. Seu escopo de proteção salvaguarda, por exemplo, o direito ao respeito pela vida privada ou ao livre desenvolvimento da personalidade, ${ }^{6}$ liberdade de

5 Quanto à liberdade negativa, cf. BERLIN, Isaiah. Two Concepts of Liberty. In: BERLIN, Isaiah. Four Essays on Liberty. Oxford: Oxford University Press, 1969, p. 118 ss. No tocante à jurisdição do Tribunal Constitucional Federal, cf. BVerfGE 7, 198, 204 s. - Lüth -; 68, 193, 205.

$6 \quad \mathrm{CEDH}$, artigo 8 (1): “Qualquer pessoa tem direito ao respeito da sua vida privada e familiar, do seu domicílio e da sua correspondência". Carta, artigo 7ㅇ: "Todas as pessoas têm direito ao respeito pela sua vida privada e familiar, pelo seu domicílio e pelas suas comunicações". GG, artigo 2o: "Todos têm direito ao livre desenvolvimento da sua personalidade [...]". 
expressão $^{7}$ e a inviolabilidade do sigilo das telecomunicações. ${ }^{8} \mathrm{O}$ aspecto crucial é que a concepção clássica entende essas liberdades como algo dado. 0 papel do Estado é reduzido à função de limitar a liberdade em relação ao bem público ou aos direitos de outros. As reservas incluídas nos direitos fundamentais atribuem essa tarefa primordialmente ao Legislativo e Ihe possibilitam limitar as garantias das liberdades por meio de regulamentações da constituição através de leis. ${ }^{9}$ Todas as intervenções por parte do Estado necessitam de uma base legal. Essa base precisa levar em conta as exigências constitucionais relevantes, especialmente o princípio da clareza e certeza dos dispositivos legais, assim como deve fazê-lo o Poder Executivo em qualquer decisão fundamentada nessa base legal.

\subsubsection{Limitações do conceito}

A compreensão dos direitos fundamentais como proteção contra violações de direitos ou ingerências neles parece ser uma proteção abrangente e ótima da liberdade. Na verdade, porém, ela tem muitos pré-requisitos e padece de limitações por causa de sua estrutura. Visto que o conceito tradicional de proteção contra violações ou ingerências se baseia em concepções liberais de direitos fundamentais, “liberdade" é entendida como uma esfera pré-estatal ou não estatal, isto é, como uma esfera que antecede o Estado ou é externa a ele, e como "liberdade natural".$^{10} \mathrm{Em}$ consequência, os direitos fundamentais estão somente voltados à proteção de liberdades já existentes. Não se levam em consideração as precondições sociais da liberdade individual ou - expressando-o de modo mais radical e preciso - o fundamento e a inserção sociais da liberdade individual. A abordagem

7 GG, artigo 5 (1): “Todos têm o direito de expressar e divulgar livremente o seu pensamento por via oral, por escrito e por imagem [...]".

8 GG, artigo 10 (1): "O sigilo da correspondência, assim como das comunicações postais e da telecomunicação, é inviolável”.

9 Cf. CEDH, artigo 8 (1): "Não pode haver ingerência da autoridade pública no exercício deste direito senão quando esta ingerência estiver prevista na lei e constituir uma providência que, numa sociedade democrática, seja necessária para a segurança nacional, para a segurança pública, para o bem-estar económico do país, a defesa da ordem e a prevenção das infrações penais, a proteção da saúde ou da moral, ou a proteção dos direitos e das liberdades de terceiros". Carta, artigo 52 (1): "Qualquer restrição ao exercício dos direitos e liberdades reconhecidos pela presente Carta deve ser prevista por lei e respeitar o conteúdo essencial desses direitos e liberdades. Na observância do princípio da proporcionalidade, essas restrições só podem ser introduzidas se forem necessárias e corresponderem efetivamente a objetivos de interesse geral reconhecidos pela União, ou à necessidade de proteção dos direitos e liberdades de terceiros". GG, artigo 5ㅇ( (2): "Estes direitos têm por limites as disposições das leis gerais, os regulamentos legais para a proteção da juventude e o direito da honra pessoal".

10 BÖCKENFÖRDE, Ernst-Wolfgang. Grundrechtstheorie und Grundrechtsinterpretation. Neue Juristische Wochenschrift (NJW), p. 1.529, 1.532, 1974; LÜBBE-WOLFF, Gertrude. Die Grundrechte als Eingriffsabwehrrechte. Baden-Baden: Nomos, 1988, p. 75 ss. 
também implica assuntos ou interesses específicos que devem ser protegidos pelos direitos fundamentais. Eles são concebidos como individualistas, isto é, de uma perspectiva que enfoca o indivíduo e na forma de um bem individual que não está já estruturalmente limitado. ${ }^{11}$ A tutela é concedida, em particular, à autodeterminação individual, a decisões e comportamentos individuais de acordo com a vontade da pessoa, ao corpo da própria pessoa ou à propriedade.

No pensamento liberal sobre os direitos fundamentais, o Estado aparece exclusivamente como uma instituição que limita as possibilidades individuais de decidir ou agir livremente. Essas limitações precisam ser justificadas, a saber, pela aprovação, por parte do Parlamento, de uma lei que persiga um objetivo legítimo, que seja tão precisa quanto possível tanto em suas exigências jurídicas quanto em suas consequências jurídicas e que seja comensurável com o princípio da proporcionalidade. Essas leis orientam e limitam as decisões do Executivo. Assim como o conceito de liberdade e o escopo da tutela de direitos individuais são moldados de formas específicas, o papel das leis e as exigências da elaboração de leis são direcionados exclusivamente para a justificação das limitações da liberdade. O papel multidimensional da legislação é desconsiderado.

\subsection{Autodeterminação informacional como direito protegido}

O conceito clássico liberal de direitos fundamentais também caracteriza a forma pela qual são descritos os bens tutelados pela proteção de dados. Isso se aplica de modo especialmente claro ao direito à autodeterminação informacional. Este é o direito fundamental decisivo no âmbito da proteção de dados na Alemanha. Entretanto, ele também está sendo mencionado com maior frequência no debate transnacional e europeu como um direito central digno de proteção. ${ }^{12}$ Há diversos debates doutrinários ou acadêmicos em andamento a respeito de como esse direito deve ser entendido ou concretizado. Esta seção analisa o direito à autodeterminação informacional levando em conta a influente jurisprudência do Tribunal Constitucional Federal alemão, que o desenvolveu e estabeleceu. Ao

ALBERS, Marion. Informationelle Selbstbestimmung. Baden-Baden: Nomos, 2005, p. 30 ss.

12 Cf. SCHWARTZ, Paul. The Computer in German and American Constitutional Law: Towards an American Right of Informational Self-Determination. Am. J. Comp. L., v. 37, p. 675 (677 ss., 701), 1989. Cf. também RAAB, Charles; GOOLD, Benjamin. Protecting Information Privacy. Equality and Human Rights Commission Research Report series, 2011, 17. Com considerações sobre as distinções, ROUVROY, Antoinette; POULLET, Yves. The Right to Informational Self-Determination and the Value of Self-Development: Reassessing the Importance of Privacy for Democracy. In: GUTWIRTH et al., 2009, p. 45, 52 ss. Quanto a um panorama dos direitos constitucionais em países europeus, cf. LEENES, Ronald; KOOPS, Bert-Jaap; HERT, Paul de (Ed.). Constitutional Rights and New Technologies. The Hague: Asser Press, 2008. 
menos neste tocante, a construção desse direito e a descrição de seu escopo de proteção se baseiam em conceitos doutrinários tradicionais e são, por conseguinte, insuficientes.

O Tribunal Constitucional Federal derivou o direito à autodeterminação informacional do direito geral de personalidade garantido pelo artigo $2 \circ$ em conjunto com o artigo $1^{\circ}$ da GG $^{13}$ em sua decisão de 1983 relativa ao Censo. ${ }^{14} \mathrm{O}$ direito à autodeterminação informacional confere ao indivíduo o poder de, em princípio, determinar por si mesmo a divulgação e uso de seus dados pessoais. ${ }^{15}$ Os indivíduos têm o direito de decidir por conta própria se e como seus dados pessoais devem ser divulgados e usados, ou, em outras palavras, um direito à autodeterminação referente ao processamento de dados relacionados a eles.

Como é que o Tribunal Constitucional Federal se deparou com essa questão a ser protegida chamada "autodeterminação informacional"? Seu precursor é o direito à privacidade, que também está consagrado no artigo 20 em conjunto com o artigo $1^{\circ}$ da GG e foi reconhecido na jurisprudência do Tribunal Constitucional Federal desde a década de 1970. Originalmente, o Tribunal concebeu esse direito empregando a imagem espacial de áreas de recolhimento isoladas do mundo exterior, ou, de modo semelhante, situações isoladas para interação e comunicação, e como direito de ficar sozinho, ou como o direito de manter confidenciais acontecimentos nessa esfera isolada. ${ }^{16} \mathrm{O}$ direito à privacidade se centrava em uma área especificada em termos espaciais e temáticos que deve permanecer, em princípio, livre de inspeção indesejada. Esse era o conceito tradicional e estreito de privacidade. Esse conceito foi alvo da mesma crítica ampla que foi levantada no debate sobre privacidade nos Estados Unidos. O primeiro ponto da crítica enfatizava a relatividade da esfera da privacidade pessoal: ela só poderia ser descrita em termos "relativos" àqueles que receberiam informações. ${ }^{17}$ Por conseguinte, o que deveria ser protegido não era uma esfera predeterminada, e sim a capacidade do indivíduo de decidir a quem quais informações deveriam ser divulgadas. Alan Westin formulou essa ideia nesses termos já em $1972 .{ }^{18}$ O segundo aspecto da crítica salientava o fato de que a necessidade de proteção dizia

13 GG, artigo 2ㅇ: "Todos têm direito ao livre desenvolvimento da sua personalidade [...]". GG, artigo 1ㅇ: "A dignidade da pessoa humana é intangivel. Respeitá-la e protegê-la é obrigação de todo o poder público".

14 BVerfGE 65, 1, 42 ss.; 15 dez. 1983, sentença sobre o Censo. Decisões subsequentes são, entre outras, BVerfGE 78, 77, 84 ss.; 84, 192, 194 ss.; 113, 29, 46 ss.; 115, 166, 188 ss.

15 BVerfGE 65, 1, 43. Com análise da decisão e seu pano de fundo: ALBERS, 2005, p. 149 ss.; cf. também ROUVROY; POULLET, 2009, p. 52 ss.

16 BVerfGE 27, 1, 6 ss.; 27, 344, 350 ss.; 32, 373, 378 ss.; 33, 367376 ss.; 44, 353, 372 ss. Cf. também WARREN, Samuel D.; BRANDEIS, Louis D. The Right to Privacy. Harvard Law Review, v. 4-5, p. 193-220, 1890.

17 Cf. SCHLINK, Bernhard. Das Recht der informationellen Selbstbestimmung. Der Staat, v. 25, p. 233, 242, 1986; SOLOVE, Daniel. The Digital Person. New York: NYU Press, 2004, p. 212 s.

18 WESTIN, 1970, p. 42. 
menos respeito à esfera privada como contexto em que certos dados surgem, e sim a que informações poderiam ser derivadas de dados obtidos e a como essas informações poderiam ser usadas. ${ }^{19} \mathrm{Em}$ outras palavras, o que é decisivo não é o contexto do qual os dados se originam, e sim o contexto em que as informações são usadas. O Tribunal Constitucional Federal reagiu a esses pontos centrais da crítica do conceito bastante estreito do direito à privacidade entendido como uma esfera protegida desenvolvendo a ideia de um direito à autodeterminação informacional que se centra nas capacidades de tomadas de decisão do indivíduo, bem como no contexto de uso. ${ }^{20} \mathrm{O}$ Tribunal também retomou os bens reconhecidos e constitucionalmente protegidos da autonomia e da liberdade de decisão e ação, argumentando que a decisão e ação livres só são possíveis sob certas circunstâncias. Se uma pessoa não tem certeza se comportamentos desviantes poderão ser armazenados como informação e usados para o detrimento dela, essa pessoa tentará não atrair atenção por tal comportamento e não é mais livre para agir segundo sua vontade. ${ }^{21}$ Essa é a razão pela qual a proteção dos direitos fundamentais deve incluir a proteção contra o processamento de informações e dados por parte do Estado. O Tribunal Constitucional Federal definiu, então, o alcance da tutela fazendo referência à liberdade de decisão e ação. Assim como as pessoas podem decidir a respeito de suas ações, da mesma maneira têm o direito de determinar como "seus" dados pessoais serão processados.

$\mathrm{O}$ que caracteriza esse direito à autodeterminação informacional? Seu alcance é maior do que a compreensão clássica do direito à privacidade. Seu elemento central é um direito individual relativamente abstrato e, por isso, amplo de tomar decisões, que se estende desde a divulgação de dados até seu processamento e seu uso. Embora o direito à autodeterminação informacional seja derivado do direito ao livre desenvolvimento da personalidade do indivíduo e da dignidade humana, ${ }^{22}$ seu escopo de proteção é definido de modo semelhante a um direito de propriedade. ${ }^{23}$ De maneira semelhante a algumas concepções americana de

19 Cf. SIMITIS, Spiros. Chancen und Gefahren der elektronischen Datenverarbeitung. NJW, p. 673, 680, 1971.

20 Quanto às fontes literárias da decisão do Tribunal, cf. HEUSSNER, Hermann (ex-ministro do Tribunal Constitucional Federal que preparou a decisão sobre o Censo). Das informationelle Selbstbestimmungsrecht in der Rechtsprechung des Bundesverfassungsgerichts. Die Sozialgerichtsbarkeit (SGb), p. 279 (280 s.), 1984. As ideias de Westin, entre outras, foram retomadas pelos ministros do Tribunal; cf. BENDA, Ernst (ex-presidente do Tribunal Constitucional Federal que participou da decisão sobre o Censo). Privatsphäre und "Persönlichkeitsprofil": Ein Beitrag zur Datenschutzdiskussion. In: LEIBHOLZ; FALLER; MIKAT; REIS (Ed.). Menschenwürde und freiheitliche Rechtsordnung. Tübingen: Mohr, 1974, p. 23 (32).

21 BVerfGE 65, 1, 43.

22 Cf. as considerações de ROUVROY; POULLET, 2009, p. 52 ss.

23 É verdade que o Tribunal também afirmou que "o indivíduo não tem um direito nos moldes de um domínio absoluto, ilimitável sobre 'seus' dados; ele é, antes, uma personalidade que se desenvolve dentro de uma comunidade humana e depende de comunicação" (BVerfGE 65, 1, 46). Entretanto, essas razões se referem à reserva que permite limitar o escopo de proteção mediante lei ordinária; elas não alteram a formulação do escopo da proteção. 
privacidade - "a privacidade", afirma Charles Fried, "é o controle que temos sobre informações a respeito de nós mesmos [...], é controle sobre conhecimentos a respeito de nós mesmos" 24 -, a autodeterminação informacional é concebida como um direito de controle sobre dados pessoais. ${ }^{25}$ Os titulares de direitos fundamentais também têm o direito de saber por quem e com que finalidade dados pessoais referentes a eles são processados, ${ }^{26}$ mas esse direito é acessório no contexto do conceito.

O direito fundamental protege esse direito de decidir a respeito da divulgação, processamento e uso de dados pessoais como uma proteção individual contra qualquer violação ou ingerência. A consequência desse escopo de proteção é que, como uma questão de princípio, cada passo no processamento de dados pessoais deve ser considerado uma violação do direito à autodeterminação informacional ou uma ingerência nele. Portanto, cada passo no processamento de dados pessoais precisa se basear ou em consentimento ou - o que é mais importante ${ }^{27}$ - em um fundamento jurídico constitucional que tem de cumprir as exigências dos princípios da clareza e determinidade e da proporcionalidade. ${ }^{28}$ Além disso, o Tribunal Constitucional Federal enfatizou o princípio da especificação antecipada das finalidades do processamento de dados e o princípio de que o processamento ulterior de dados está vinculado à finalidade original. ${ }^{29}$ Essas consequências já mostram a ampla influência que esse conceito de autodeterminação informacional tem sobre as leis de proteção de dados.

Na Alemanha, o direito à autodeterminação informacional está muito firmemente ancorado e tem muitas ramificações. É verdade que o Tribunal Constitucional Federal continuou desenvolvendo esse direito e chegou a uma jurisprudência cada vez mais diferenciada, ocasionalmente ambivalente. ${ }^{30}$ Entretanto, o enfoque básico do Tribunal fica preso tanto à descrição do escopo de proteção descrito na sentença sobre o Censo quanto aos padrões tradicionais do pensamento dogmático. O Tribunal constata, via de regra, que a autodeterminação informacional protege “a competência do indivíduo de, basicamente, determinar por conta própria

24 FRIED, Charles. Privacy. Yale Law Journal, v. 77, p. 475, 482, 1968.

25 Para um panorama dos conceitos americanos tradicionais e influentes, veja SOLOVE, Daniel. Conceptualizing Privacy. California Law Review, v. 90, p. 1.088, 1.099 ss., 2002. Com uma consideração adicional dos desdobramentos em nível internacional e europeu, cf. também GRATTON. Understanding Personal Information: Managing Privacy Risks, 2013, p. 1 ss.

26 BVerfGE 65, 1, 46.

27 O cerne do direito à autodeterminação informacional não é que o consentimento tenha de desempenhar um papel-chave. Mais importante em termos teóricos e práticos é que uma base jurídica constitucional é necessária para justificar o processamento de dados.

28 BVerfGE 65, 1, 44 ss.

29 BVerfGE 65, 1, 46.

30 Cf. ALBERS, Marion. Umgang mit personenbezogenen Informationen und Daten. In: HOFFMANN-RIEM; SCHMIDT-ASSMANN; VOSSKUHLE (ed.). Grundlagen des Verwaltungsrechts II. 2. ed. 2012, §22 n. 62 ss. 
a respeito da entrega e utilização de seus dados pessoais". ${ }^{31}$ É verdade que as exigências jusconstitucionais concretas às leis ou a medidas por parte de órgãos públicos e a decisões de tribunais foram diferenciadas e refinadas ao longo do tempo. ${ }^{32}$ Até agora, porém, o Tribunal Constitucional Federal ainda não se adequou de modo suficientemente coerente às características e exigências de uma proteção orientada justamente por informações e dados.

\subsection{Influência sobre abordagens e princípios da proteção de dados}

Os padrões de pensamento acima ilustrados e a forma pela qual os bens a serem tutelados pela proteção de dados marcam as abordagens, princípios, construtos jurídicos e leis concernentes à proteção de dados até a atualidade. Eles também influenciaram, por exemplo, o direito fundamental expresso no artigo 8 da Carta dos Direitos Fundamentais da UE e na Regulamentação Geral da Proteção de Dados da União Europeia por meio de influências recíprocas na legiferação. De modo semelhante, afetam as decisões dos tribunais por meio da rede jurisdicional existente entre o Tribunal Constitucional Federal alemão, a Corte Europeia de Direitos Humanos e o Tribunal de Justiça Europeu. ${ }^{33}$

$\mathrm{O}$ direito à privacidade ou o direito à autodeterminação informacional, definido como o direito individual de decidir sobre a divulgação, processamento e uso de dados pessoais, centra-se em dados, especificamente nos dados pessoais avulsos, e, em sentido mais amplo, em seu processamento em uma sequência de passos predefinidos - coleta, armazenamento, alteração, uso, transferência. Além disso, os termos "dados" e "informações" são tratados como se fossem sinônimos. Isso reflete um conceito ôntico de informação, a saber, a ideia de que a informação é uma espécie de retrato da realidade e de que os dados podem ser

31 Cf. recentemente BVerfG, sentença emitida em 19 abr. 2016, 1 BvR 3309/13, n. 56, <www.bverfg. de>. Em algumas decisões, podem-se encontrar relativizações, mas elas não produziram mudanças conceituais; cf. BVerfGE 115, 320 (342 ss.); 118, 168 (185); 120, 378 (399); 130, 151 (183 s.).

32 Cf. BVerfGE 100, 313, 360 s.; 109, 279, 379 s.; 115, 320, 359 ss.; 118, 168, 186 ss.; 120, 351, 366 ss.; 120, 378, 407 ss.; 125, 260, 325 ss.; 130, 151, 187 ss.; 133, 277, 320 ss.; BVerfG, decisão tomada em 20 abr. 2016, 1 BvR 966/09 et al., <www.bverfg.de>, n. 93 ss.

33 No tocante à proteção de dados na jurisprudência da Corte Europeia de Direitos Humanos e do Tribunal de Justiça Europeu, cf. HERT, Paul de; GUTWIRTH, Serge. Data Protection in the Case Law of Strasbourg and Luxemburg: Constitutionalisation in Action. In: GUTWIRTH et al., 2009, p. 3, 14 ss.; SIEMEN, Birte. Datenschutz als europäisches Grundrecht. Berlin: Duncker \& Humblot, 2006, p. 51 ss.; SCHWEIZER, Rainer. Die Rechtsprechung des Europäischen Gerichtshofes für Menschenrechte zum Persönlichkeitsund Datenschutz. DuD, p. 462, 464 ss., 2009. 
tratados como se fossem objetos. Concepções desse tipo ocorrem nas abordagens básicas e nas definições jurídicas do direito referente à proteção de dados. Visto que a autoridade do indivíduo de decidir sobre o processamento de dados pessoais está protegida, cada passo do processamento de dados pessoais exige ou consentimento, ou uma base jurídica. Essa abordagem se orienta pela ideia de que as alternativas de ação e os processos de tomada de decisão poderiam ser previstos, planejados e controlados por meios legais. Na Alemanha, isso resultou em uma ampla juridificação e em uma grande quantidade de leis de proteção de dados, que, contudo, muitas vezes simplesmente mapeiam os passos do processamento de dados.

Entretanto, a proteção de dados depende de uma definição que corresponda aos objetivos da proteção, passando por diversos níveis e formas do direito. Para tanto, é preciso elaborar componentes complexos e diversificados, que têm de ser articulados tanto com as regulamentações da matéria quanto uns com os outros. Isso fica claro quando se explicita melhor o que a proteção de dados compreende exatamente e quão complexa ela precisa ser.

\section{A complexidade da proteção de dados: análises e consequências}

O direito relativo à proteção de dados tem estado em fluxo há algum tempo. Muitas vezes foram destacadas mudanças ocorridas nas condições básicas da sociedade e da tecnologia. Mas o problema de modo algum se resume simplesmente a uma adaptação a mudanças nas condições externas. Em um nível fundamental, os padrões de pensamento e descrição usados na legislação sobre a proteção de dados precisam ser refletidos criticamente e reconceitualizados.

Isso será explicado no tocante a três pontos em particular: primeiro, no tocante ao assunto em pauta; em segundo lugar, no tocante à descrição dos interesses protegidos; e, em terceiro lugar, no tocante aos conceitos de regulamentação. Em decorrência disso, ficará claro que, em todos os sentidos, a proteção de dados exige uma abordagem inovadora, é altamente complexa e coloca desafios inéditos para o direito.

\subsection{A complexidade do assunto: dados e informações, conhecimento e fluxo de dados e informações, decisões e consequências de decisões}

O objetivo da proteção de dados não é a proteção de dados, mas dos indivíduos aos quais os dados se referem. O objeto da proteção, portanto, não são 
os dados pessoais em si. ${ }^{34}$ Precisamos ampliar essa concepção isolada incluindo vários elementos: em um nível básico, o elemento da informação; na dimensão estrutural, o conhecimento; na dimensão temporal, o fluxo de dados e informações; e, no contexto mais amplo, decisões e consequências de decisões.

Os conceitos de "dados" e "informação" são definidos de maneiras multifárias e dependentes da respectiva disciplina. ${ }^{35}$ No contexto (social) da proteção de dados, é ao menos importante dar-se conta de que dados e informação não são sinônimos. Esses termos devem, pelo contrário, ser diferenciados rigorosamente. Dados podem ser descritos como caracteres gravados em um suporte de dados, incluindo documentos escritos ou vídeos, bem como dados armazenados digitalmente em discos rígidos ou dispositivos móveis de armazenamento. ${ }^{36}$ Os dados, as formas de armazenamento e as operações de processamento são caracterizados pelas várias mídias, tecnologias e redes. ${ }^{37}$ Devido à sua objetificação, os dados podem ser concebidos de modo distinto e oferecem um ponto de partida para a regulamentação jurídica. Não obstante, os dados não são significativos em si mesmos, e sim como "informação em potencial”. Seu conteúdo informacional não é um atributo intrínseco dos próprios dados. ${ }^{38}$ Ele só é criado por meio de interpretação no contexto particular da interpretação.

A informação implica sentido, e informações avulsas são elementos de sentido. Unidades de informações podem se basear em dados (ou em observações ou comunicações), mas os dados só adquirem sentido ao serem explicados e interpretados por quem recebe ou usa os dados para obter informação. A elaboração de sentido depende das condições situacionais individuais para a interpretação e do contexto do conhecimento e da interpretação. ${ }^{39}$ A informação depende do contexto de uma maneira elementar. Embora essa percepção talvez esteja bem estabelecida atualmente, as pessoas dificilmente percebem as dificuldades que isso acarreta para a regulamentação legal e para uma descrição do objeto a ser regulamentado.

34 Com isso se relativiza de modo significativo a importância jurídica da "relação com a pessoa". Esta última pode ser difícil de constatar e, não raro, só aparece no contexto ou transcurso das redes e passos do processamento (sobre isso, cf. GRATTON, 2013, p. 21 ss., 93 ss.). Além disso, dessa maneira a proteção de dados pode ser mais bem combinada com vínculos jurídicos e posições protetivas que precisam ser desenvolvidos - por exemplo, proteção contra a discriminação - nas áreas em que não estão em pauta informações e dados referentes a pessoas.

35 Cf., por exemplo, FLORIDI, Luciano. Information: A Very Short Introduction. 2010, p. 19 ss.

36 Ilustrações de conceitos de dados em KITCHIN, Rob. The Data Revolution. Los Angeles: Sage, 2014, p. 2 ss.

37 Cf., entre outros, WALDO, James; LIN, Herbert S.; MILLETT, Lynette I. (Ed.). Engaging Privacy and Information Technology in a Digital Age. 2007, p. 88 ss.

38 Cf., no tocante à comunicação, ASHBY, William. An Introduction to Cybernetics. 5. ed. London: Chapman \& Hall, 1963, p. 124: “A informação transmitida não é uma propriedade intrínseca da mensagem individual".

39 ALBERS, Marion. Information als neue Dimension im Recht. Rechtstheorie, v. 33, p. 61, 67 ss., 2002. Cf. também BATESON, Gregory. Steps to an Ecology of Mind. Chicago: University of Chicago Press, 1972, p. 315 ss. 
Devido ao fato de que a informação exige interpretação, que ocorre em um contexto particular de conhecimento e interpretação e depende das condições individuais e situacionais da interpretação, a informação se refere, antes de tudo, às estruturas e aos processos dentro dos quais ela pode ser criada. Na dimensão estrutural, o conhecimento está implicado na geração de informações. 0 conhecimento está fundamentado em textos, arquivos, registros, bancos de dados, sistemas especialistas, mas também em arranjos institucionais, organizacionais ou procedimentais. Ele torna possível a interpretação e limita as possibilidades de interpretação. O conhecimento é um fator e um produto do contexto em que ocorre o tratamento de informações e dados, e influencia esse tratamento de modo inerente. ${ }^{40} \mathrm{~A}$ possibilidade de o processamento de dados representar (ou não) um risco para a pessoa à qual os dados se referem depende do conhecimento que existe ou pode ser desenvolvido em um contexto particular ou em um caso particular. É por isso que a proteção de dados também precisa levar em conta o nível de conhecimento. ${ }^{41} \mathrm{Na}$ dimensão temporal, o caráter procedimental do processamento de dados também entra em jogo. Dados e informações são constantemente gerados de novo e alterados durante as operações de processamento. Além disso, uma coleção de dados pessoais só revela seu sentido social e jurídico quando ela é vista junto com suas ligações com outros dados, seu uso ou sua transferência para outras agências. Por exemplo, só se pode entender o que significa que dados telecomunicacionais pessoais sejam armazenados mais tempo do que o necessário para a cobrança (no contexto da retenção de dados) levando em conta os deveres das empresas de telecomunicação de transmitirem dados pessoais às autoridades de segurança, que, então, usam os dados para investigações ulteriores contra a respectiva pessoa. ${ }^{42}$

As maneiras pelas quais dados e informações são tratados, o conhecimento e as operações de processamento são impactados pelas mídias, tecnologias e redes empregadas. Se os dados são armazenados (ou não) em arquivos de papel, arquivos eletrônicos automatizados ou sistemas de redes exercem uma influência, por exemplo, sobre a quantidade e a forma dos dados que podem ser armazenados e acessados com facilidade, sobre os potenciais para interligá-los ou sobre as possibilidades de transmitir dados. As mídias, tecnologias e redes

40 ALBERS, 2012, n. 14 ss.; TRUTE, Hans-Heinrich. Wissen - Einleitende Bemerkungen. In: RÖHL (ed.). Wissen - Zur kognitiven Dimension des Rechts, Die Verwaltung, suplemento 9, 2010, 11 ss.

41 Cf. também HILDEBRANDT, Mireille. Who is Profiling Who? Invisible Visibility. In: GUTWIRTH et al., 2009, p. 239,240 ss.

42 Cf. BVerfGE 125, 260 (318 ss.). Quanto a uma avaliação crítica dessa decisão, cf. VRIES, Katja de; BELLANOVA, Rocco; HERT, Paul de; GUTWIRTH, Serge. The German Constitutional Court Judgment on Data Retention: Proportionality Overrides Unlimited Surveillance (Doesn't It?). In: GUTWIRTH et al. Computers, Privacy and Data Protection: An Element of Choice. Dordrecht: Springer, 2011, p. 3 ss. 
podem aumentar os perigos a que os indivíduos estão sujeitos, mas certamente também limitam essa vulnerabilidade introduzindo barreiras e salvaguardas técnicas relacionadas ao processamento de dados.

O que importam, igualmente, são as conexões entre a informação ou o conhecimento, por um lado, e as decisões tomadas pelos órgãos públicos ou privados que processam os dados, por outro. No final das contas, a informação e o conhecimento servem de base para certas decisões e ações. Essas decisões têm consequências. Elas podem ter um efeito adverso sobre a pessoa à qual os dados se referem na forma de uma limitação da liberdade dela. E a proteção de adversidades ou desvantagens injustificadas é uma das razões para a proteção de dados.

Portanto, a proteção de dados lida com um assunto altamente complexo: é necessário operar com a diferenciação entre dados e informações. A dimensão do conhecimento e a dimensão temporal do fluxo de dados e informações precisam ser levadas em consideração, bem como as decisões e consequências de decisões. Em outras palavras, qualquer novo conceito estaria equivocado se enfocasse apenas as informações, e não os dados, e simplesmente substituísse um termo pelo outro. Pelo contrário, os dados continuam sendo um importante ponto de referência para a regulamentação jurídica. Mas os dados precisam ser concebidos dentro de uma rede de vários elementos fundamentais e não constituem o único ponto de referência. A proteção de dados visa regulamentar o processamento de dados, mas precisamente também regulamentar a geração de informações e conhecimentos, influenciar as decisões baseadas nessa geração e prevenir consequências adversas para os indivíduos afetados.

\subsection{A complexidade dos interesses protegidos dos indivíduos afetados}

Isso nos leva ao segundo ponto: como podemos descrever os interesses protegidos dos indivíduos afetados? No centro da discussão jurídica, estão algumas poucas descrições formuladas muito abstratamente de bens protegidos juridicamente, que estão relacionados com direitos fundamentais: vida privada ou privacidade, ${ }^{43}$ proteção de dados pessoais, autodeterminação informacional. 0 artigo $8^{\circ}$ da $\mathrm{CEDH}$, o direito ao respeito pela vida privada, ${ }^{44}$ foi concretizado em várias ações contra a coleta e o armazenamento de dados pessoais ou demandas para

43 Para uma análise do conceito de "privacidade informacional" no Reino Unido, veja RAAB; GOOLD, 2011.

44 Cf. nota 6. 
serem informados sobre dados que se referem à pessoa. Entretanto, as decisões judiciais da Corte Europeia de Direitos Humanos se desdobram de caso em caso; os conteúdos do que constitui o direito ao respeito pela "vida privada" como bem juridicamente tutelado é compilado de modo meramente casuístico. ${ }^{45}$ Olhandose 0 artigo $7^{\circ}$ da Carta da EU, ${ }^{46}$ o artigo 16 (1) do Tratado de Funcionamento da União Europeia e o artigo $8^{\circ}$ da Carta da EU, ${ }^{47}$ constata-se que o direito ao respeito pela "vida privada" e o direito à "proteção de dados pessoais" - cada um deles um bem juridicamente protegido que é formulado de maneira muito abstrata - se encontram lado a lado. Até hoje, o Tribunal de Justiça Europeu evita uma diferenciação inequívoca ${ }^{48}$ e só descreve especificamente objetivos de proteção e bens juridicamente protegidos em um grau muito limitado. O Tribunal Constitucional Federal se concentra na "autodeterminação informacional" derivada do artigo $2^{\circ}$ em conjunto com o artigo 1ำ da GG como um bem juridicamente protegido. De igual maneira, as abordagens acadêmicas na Alemanha há muito se centram em padrões de pensamento, como a autodeterminação informacional, a autoridade de decidir a respeito do processamento de dados pessoais e o controle individual. Em anos recentes, tem havido algum movimento e teve início uma nova discussão sobre os direitos que a proteção de dados deveria salvaguardar. Uma crítica muito disseminada sustenta que o controle simplesmente não é possível por causa das circunstâncias factuais e das condições da internet. Mas a abordagem adotada por essa crítica não é profunda o suficiente. A ideia de controle sobre os próprios dados é falha, não só porque ela não seria mais praticável. É falha porque não combina com a questão a ser protegida. Faz-se necessária uma reconceitualização que deixe para trás o conceito clássico de direitos básicos. Os interesses que a proteção de dados deve salvaguardar não podem ser apreendidos usando-se uma perspectiva individualista; é preciso uma compreensão multidimensional de direitos fundamentais; e, em decorrência disso, a proteção de dados inclui um conjunto de direitos que precisam ser descritos de uma maneira nova.

45 Cf. as referências na nota 33.

46 Cf. nota 6.

47 Carta, art. 8 (1): “(1) Todas as pessoas têm direito à proteção dos dados de caráter pessoal que Ihes digam respeito. (2) Esses dados devem ser objeto de um tratamento leal, para fins específicos e com o consentimento da pessoa interessada ou com outro fundamento legítimo previsto por lei. Todas as pessoas têm o direito de aceder aos dados coligidos que lhes digam respeito e de obter a respectiva retificação. (3)

O cumprimento destas regras fica sujeito a fiscalização por parte de uma autoridade independente".

48 Cf., por exemplo, Tribunal de Justiça Europeu, Rs. C-92/09 e C-93/09, Schecke and Eifert vs. Land Hessen, <http://curia.europa.eu>, §§45 ss. A diferenciação é necessária, mas não é fácil por causa da interação entre o artigo 7ํ da Carta da União Europeia em conjunto com o artigo 52 (3) da Carta, artigo $8^{\circ}$ da Convenção Europeia de Direitos Humanos, por um lado, e o artigo 8o da Carta, por outro. 


\subsubsection{De padrões individualistas para a proteção do indivíduo na socialidade}

A proteção de direitos fundamentais em termos da maneira como as agências governamentais ou outras partes privadas lidam com as informações e os dados pessoais é diferente do bem juridicamente protegido na compreensão tradicional de direitos fundamentais. É verdade que existe um titular de direitos fundamentais. Mas o objeto da proteção não é a liberdade de decisão ou de ação do titular, que ficaria prejudicada pela intervenção estatal. Em vez disso, como a análise do assunto acaba de demonstrar, o titular deve ser protegido em termos de informações e dados pessoais, que são gerados e processados por outros em contextos particulares. Agências governamentais ou outros órgãos privados estão estruturalmente implicados nisso devido ao mero fato de que dados e informações precisam ser interpretados. Informações ou dados pessoais não podem ser atribuídos à pessoa em questão como um objeto que pertença a ela. ${ }^{49}$ Padrões individualistas de atribuição são insuficientes.

O raciocínio sobre a razão pela qual e até que ponto a pessoa em questão deve ser protegida precisa, pelo contrário, provir de uma perspectiva supraindividual, a saber, assumindo-se uma visão categorizadora do contexto e das consequências adversas a serem esperadas em relação à pessoa à qual se referem os dados, as informações e o conhecimento. O mero fato de que uma informação avulsa se refere a uma pessoa ainda não implica a necessidade de proteção de uma pessoa. A necessidade de proteção surge, em particular, em relação aos efeitos negativos do tratamento dos dados pessoais e das informações obtidas a partir dele. Os bens juridicamente protegidos e os mecanismos de violação ou ingerência exigem seus próprios padrões separados de descrição. Além disso, a proteção direcionada unicamente à defesa contra o processamento de dados pessoais e ao impedimento desse processamento é insuficiente. A pessoa protegida também pode ter interesse em que dados pessoais sejam disponibilizados de modo que um órgão ou agência tenha à sua disposição as informações de que necessita para tomar uma decisão correta. E é igualmente importante que a pessoa afetada seja informada sobre o processamento de dados e informações pessoais e possa influenciá-lo. Portanto, os indivíduos necessitam não só de direitos defensivos, mas também de direitos de saber, de obter informação, de participar e de exercer influência. Por conseguinte, a questão a ser protegida pela proteção de dados com base em direitos fundamentais precisa ser elaborada de

49 Uma análise mais completa se encontra em ALLEN, Anita L. Privacy-As-Data Control: Conceptual, Practical, and Moral Limits of the Paradigm. Connecticut Law Review, v. 32, p. 861, 865 ss., 2000. 
modo diferente e ser mais diversificada do que os bens juridicamente tutelados em termos do conceito "clássico" de direitos fundamentais e do conceito "clássico" de proteção contra violações ou ingerências. A proteção apropriada de dados exige uma concepção mais sofisticada de direitos fundamentais.

\subsubsection{A necessidade de basear-se em uma compreensão multidimensional de direitos fundamentais}

Atualmente, as ampliações das funções dos direitos fundamentais e do escopo de sua proteção que vão além da compreensão tradicional dos direitos fundamentais são reconhecidas em princípio. As codificações modernas, como a Carta de Direitos Fundamentais da UE, por exemplo, refletem a diversidade das dimensões de proteção em seus catálogos de direitos fundamentais. ${ }^{50} \mathrm{O}$ Tribunal Constitucional Federal alemão derivou obrigações positivas do Estado, por exemplo, obrigações de proporcionar a renda mínima necessária para a existência e especialmente o dever de proteção (Schutzpflicht) por parte do Estado, bem como a chamada eficácia horizontal (Drittwirkung) pela qual os direitos fundamentais influenciam indiretamente as relações jurídicas entre pessoas privadas. Não obstante, as decisões do Tribunal Constitucional Federal, da Corte Europeia de Direitos Humanos e do Tribunal de Justiça Europeu são tentativas neste tocante. A proteção contra violações ou ingerências ainda é considerada a dimensão primária da proteção nos direitos fundamentais. Essa é uma das razões pelas quais, no caso da proteção de dados, os direitos protegidos são definidos de modo semelhante a um direito de propriedade. Razões doutrinárias também se evidenciam em relação ao reconhecimento um tanto hesitante de direitos fundamentais de acesso a dados pessoais ${ }^{51}$ ou de garantias institucionais. Em debates

50 Cf., por exemplo, artigo 14, artigos 27 e ss. da Carta.

51 Na Alemanha, a decisão da Primeira Turma do Tribunal Constitucional Federal que derivou fundamentalmente os direitos de tomar conhecimento não apenas da garantia de acesso aos tribunais, artigo 19 (4) da GG, mas também do artigo 2ำ (1) em conjunto com o artigo 1ํㅗㄱ da GG, só ocorreu em 2018; cf. BVerfGE 120, 351 (362 ss.); quanto ao período anterior, cf. BVerfG (decisão de câmara), NJW, p. 1.116 (1.117 ss.), 2006. A Corte Europeia de Direitos Humanos reconheceu direitos de acesso a arquivos pessoais e de obtenção de informações mais cedo, porém na maioria das vezes em casos especiais; veja, sobre o direito de as pessoas receberem as informações necessárias para entender sua infância e desenvolvimento, CEDH, Gaskin vs. United Kingdom, sentença de 7 jul. 1989, Requerimento № 10.454/83, e sobre o direito de acesso a dados (não necessariamente pessoais) relacionados à saúde, CEDH, McGinley and Evan vs. UK, sentença de 9 jun. 1998, Requerimentos no 21.825/93, 23.414/94 -, n. 98 ss.; cf. também CEDH, Segerstedt-Wiberg, sentença de 6 jul. 2006, Requerimento no 62.332/00 -, n. 99 ss. A Corte argumenta com cautela: "Embora o objeto do artigo 8 seja essencialmente a proteção do indivíduo contra interferência arbitrária por parte das autoridades públicas, ele não se limita a obrigar o Estado a se abster de tal interferência; além dessa ação primordialmente negativa, pode haver obrigações positivas 
acadêmicos, os fundamentos, o alcance e os detalhes de dimensões ulteriores da proteção dos direitos fundamentais para além da compreensão tradicional são objeto de controvérsia acalorada.

Entretanto, as garantias abstratas dos direitos fundamentais estão abertas à intepretação e permitem que se elaborem diversas dimensões da proteção. A compreensão clássica é um conceito estreito demais e tem pré-requisitos e limitações disfuncionais. Os direitos fundamentais não têm a ver somente com proteção contra violações ou ingerências, mas também com direitos de tomar conhecimento e obter informações, com direitos de participar e influenciar decisões, com direitos de ser protegido pelo Estado ou com garantias institucionais. Como os padrões individualistas de atribuição e a ideia de controle sobre os dados da própria pessoa são insuficientes e a questão a ser protegida é multifária, a proteção de dados tem de se basear no desenvolvimento ulterior das funções e dos conteúdos dos direitos fundamentais.

\subsubsection{O conjunto de interesses protegidos}

"Proteção de dados" é um conceito bastante vago. Alguns pesquisadores enfatizam que a proteção de dados simplesmente descreve a ferramenta para salvaguardar liberdades juridicamente protegidas, como a autonomia ou a liberdade de decisão. Outros supõem que ela se refira ao bem ou aos bens a serem tutelados. Esse conceito também poderia ser entendido em um duplo sentido, como meio de proteção e, enquanto termo mais abrangente, como os interesses juridicamente protegidos. De qualquer modo, quando se trata dos bens a serem tutelados, a proteção de dados não deveria ser entendida como um conceito instrumental ou premissa preliminar que protege outras liberdades conhecidas a partir do conceito tradicional. ${ }^{52}$ É preciso, pelo contrário, deixar para trás as descrições que usam uma abordagem individualista, a saber, autodeterminação, liberdade de decisão, propriedade. Os interesses a serem protegidos deveriam ser formulados de tal maneira que obtenham seu sentido quando a socialidade do indivíduo em questão

inerentes ao respeito efetivo à vida privada ou familiar. Para determinar se tal obrigação existe ou não, a Corte considerará o equilíbrio justo que deve ser alcançado entre o interesse geral da comunidade e os interesses concorrentes do indivíduo ou indivíduos afetados [...]" (McGinley and Evan vs. UK, sentença de 9 jun. 1998, Requerimentos no 21.825/93, 23.414/94 -, n. 98).

52 São de outra opinião BRITZ, Gabriele. Informationelle Selbstbestimmung zwischen rechtswissenschaftlicher Grundsatzkritikund Beharren des Bundesverfassungsgerichts. In: HOFFMANN-RIEM, Offene Rechtswissenschaft. Tübingen: Mohr Siebeck, 2010, p. 569 ss.; POSCHER, Ralf. Die Zukunft der informationellen Selbstbestimmung als Recht auf Abwehr von Grundrechtsgefährdungen. In: GANDER, Hans-Helmuth et al. (ed.). Resilienz in der offenen Gesellschaft. Baden-Baden: Nomos, 2012, p. 178 ss. 
é levada em conta. Isso corresponde ao assunto elucidado acima: dados, informações, conhecimento. Portanto, a proteção de dados tem a ver com a proteção contra a criação de perfis de personalidade, a proteção da reputação de uma pessoa, a proteção contra estigmatização e discriminação, a proteção de expectativas normativamente justificadas de privacidade, a proteção contra o roubo da identidade, a proteção contra vigilância e a proteção da integridade contextual. ${ }^{53}$ Esses exemplos ilustram que a proteção de dados não compreende um bem juridicamente tutelado que seja uniforme. Há, pelo contrário, interesses complexos e múltiplos que devem ser protegidos. Seu amplo alcance e sua dependência do contexto já foram elaborados no contexto dos debates sobre "privacidade" ocorridos nos EUA, por exemplo, por Daniel Solove e Helen Nissenbaum, entre outros. ${ }^{54}$

Uma análise mais detida revela que os perigos representados pelo processamento de dados e informações pessoais e as necessidades protetivas às quais a proteção de dados reage foram identificados em vários níveis. ${ }^{55}$ Em um nível básico, o problema crucial está centrado no processamento de dados e informações, que é oniabrangente, ilimitado e não transparente. Enquanto se está confrontado com uma situação desse tipo, não se pode fazer uma avaliação adequada da questão de em que contextos a informação está sendo gerada e de como essa informação está sendo usada ou de quais consequências negativas indivíduos terão de enfrentar em constelações específicas. Esse problema do processamento ilimitado e intransparente de dados precisa ser enfrentado por uma regulamentação jurídica que proporcione limites e transparência basais. Só com base nisso é possivel elaborar os interesses a serem protegidos que existem em contextos bem específicos devido a desvantagens bem específicas.

No nível básico, o Grande Irmão, de Orwell, ${ }^{56}$ o Panóptico, de Bentham ${ }^{57} \mathrm{e}$ 0 processo, de Kafka, ${ }^{58}$ poderiam ser ilustrativos como metáforas amplamente conhecidas e culturalmente ancoradas que - embora essas narrativas estejam, é claro, arraigadas em contextos bem diferentes - retomam diferentes facetas dos perigos mencionados acima. Complementando essas obras centradas no Estado,

$53 \mathrm{O}$ direito fundamental à garantia da confidencialidade e integridade de sistemas de tecnologia da informa-

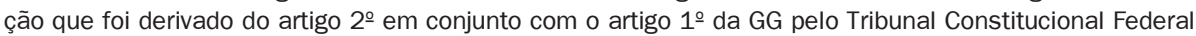
em 2008 - BVerfGE 120, 271 - aponta na direção certa, mas deveria ser entendido meramente como uma parte da proteção de dados.

54 SOLOVE, Daniel. Understanding Privacy. Cambridge: Harvard University Press, 2008; NISSENBAUM, Helen. Privacy as Contextual Integrity. Washington Law Review, v. 79, p. 119 ss., 2008; NISSENBAUM, Helen. Privacy in Context: Technology, Policy, and the Integrity of Social Life. Stanford: Stanford University Press, 2010. Cf. também RÖSSLER, Beate. Der Wert des Privaten. Frankfurt am Main: Suhrkamp, 2001.

55 Cf. ALBERS, 2005, p. 353 ss.

56 ORWELL, George. Nineteen Eighty-Four, 2008.

57 BENTHAM, Jeremy. The Panopticon Writings. Ed. Miran Bozovic. 1995, p. 29 ss.

58 KAFKA, Franz. Der Prozess. Frankfurt a.M.: S. Fischer, 2002. 
podem-se acrescentar, com vistas às redes sociais, romances mais recentes que são certeiros em relação a esse problema, como, por exemplo, O círculo, de Dave Eggers. ${ }^{59}$ Daniel Solove destacou que "a metáfora do Grande Irmão certamente é eficaz na apreensão de certos problemas de privacidade", ${ }^{60}$ mas que é a metáfora de Kafka que apreende os elementos de ameaças à privacidade que lidam com a coleta e circulação de certos dados por parte de outras pessoas ou outras entidades "sem ter qualquer voz ativa no processo, sem saber quem tem quais informações, que propósitos ou motivos essas entidades têm ou o que será feito com essas informações no futuro". ${ }^{61}$ Isso ilustra que, no nível básico, já há problemas multifários que a proteção de dados terá de enfrentar. Falando juridicamente, eles não são resolvidos pela mera atribuição de um direito individual de controlar dados pessoais ao sujeito dos dados. Em consonância com os perigos à liberdade, deveres do Poder Legislativo e exigências de regulamentação legal são necessários. A legislação precisa regulamentar o processamento de dados de modo apropriado e garantir que o tratamento de informações e dados pessoais não ocorra de maneira irrestrita, ilimitada e intransparente, e tem de assegurar que os indivíduos afetados tenham a possibilidade de obter conhecimento suficiente sobre o processamento de dados e informações pessoais e influência suficiente sobre ele. Neste nível, a presença do Estado é imprescindível.

Em um segundo nível concreto, estão em jogo interesses individuais e específicos a serem protegidos, que surgem para a pessoa afetada em contextos concretos em termos de consequências adversas. A capacidade de descrever os perigos, bem como os interesses específicos a serem protegidos neste segundo nível, exige que a regulamentação básica ocorra no primeiro nível. Um exemplo é o problema do serviço de inteligência interno monitorar uma reunião pública, com consequências negativas para a liberdade de reunião. Outro exemplo é a proteção de indivíduos contra a intrusão da mídia mediante a publicação de dados ou imagens pessoais. Neste nível, aplicam-se os direitos como proteção contra violações ou ingerências. Não obstante, também é preciso derivar deveres de proteção, e um conceito geral para além das abordagens tradicionais também é necessário.

O resultado mostra que a proteção de dados esboça um conjunto complexo de interesses dignos de tutela. A proteção de dados baseia-se em uma compreensão multidimensional de direitos fundamentais e exige descrições inteiramente novas dos interesses protegidos: em vez de bens juridicamente tutelados concebidos de modo individualista, a questão tem a ver com posições jurídicas individuais

59 EGGERS, Dave. The Circle. New York: Knopf, 2013.

60 SOLOVE, Daniel. Privacy and Power: Computer Databases and Metaphors for Information Privacy. Stanford Law Review, v. 53, p. 1.393, 1.399, 2001.

61 Ibid., p. 1.426. 
na socialidade ou, em outras palavras, as posições sociais do indivíduo a serem protegidas por direitos fundamentais. 0 conjunto de interesses e posições protegidos ainda precisa ser elaborado com maior grau de detalhamento e também terá de ser sempre adaptado dinamicamente a novos perigos. ${ }^{62}$

\subsection{A complexidade de conceitos apropriados para a regulamentação}

A terceira seção deste artigo irá demonstrar quão complexos devem ser conceitos apropriados para a regulamentação. Até hoje, os conceitos ainda se caracterizam pela imagem de computadores centrais do tipo mainframe, que processam dados usando programas em uma sequência predefinida. Juridicamente, a autodeterminação informacional como bem a ser protegido e a reserva que permite a regulamentação legal levam à ideia de que cada passo no processamento de dados pessoais precisa ser justificado por consentimento ou regulamentado juridicamente por meio de uma base na legislação. Entrementes, porém, as armadilhas do consentimento são reconhecidas, e a grande quantidade de leis é cada vez mais criticada por representar uma enxurrada de legislação. Mais problemático do que a quantidade de leis é o fato de que muitas vezes as regulamentações simplesmente mapeiam os passos do processamento de dados e de que a abordagem se caracteriza pela crença no planejamento prevalente no século passado, quando as pessoas estavam convencidas de que era possivel regulamentar as coisas com precisão usando meios legais. ${ }^{63}$

Entretanto, os direitos fundamentais como base da proteção de dados não resultam na obrigação de entender as leis sobre o pano de fundo do papel tradicional delas. Além de permitir o desenvolvimento de novos bens juridicamente tutelados, os direitos fundamentais permitem uma compreensão multidimensional das reservas e das regulamentações. As normas jurídicas não só limitam liberdades. Elas também podem, antes de tudo, criar liberdades, torná-las concretas e influenciar suas condições e pré-requisitos sociais. 0 direito referente à proteção de dados deve estar fundamentado nas diversas funções e diversas formas do direito. Os conceitos de regulamentação precisam incluir uma ampla gama de

62 Também enfatizam a necessidade de uma descrição precisa de perigos e obstruções, ainda que com base em abordagens diferentes, GRATTON, 2013, p. 219 ss.; DRACKERT, Stefan. Die Risiken der Verarbeitung personenbezogener Daten. Berlin: Duncker \& Humblot, 2014.

63 Sobre novos desafios referentes à computação ubíqua, que afeta os princípios atuais da proteção de dados, cf. ČAS, Johann. Ubiquitous Computing, Privacy and Data Protection: Options and Limitations to Reconcile the Unprecedented Contradictions. In: GUTWIRTH et al., 2009, p. 139, 141 ss. 
elementos constitutivos, que utilizem todo o espectro de formas e instrumentos jurídicos. Eles são, portanto, complexos em seus próprios termos e, além disso, têm de ser entrelaçados. Outros fatores deixam claro quão desafiantes são leis apropriadas de proteção de dados.

\subsubsection{Uma ampla gama de elementos regulatórios}

Em vez de meramente guiar os passos do processamento de dados, conceitos apropriados de regulamentação exigem muitos elementos diferentes. A regulamentação dos estágios do processamento de dados ainda desempenhará um papel importante no futuro. Entretanto, essa forma de regulamentação é suplementada e incrementada por outros elementos constitutivos: proteção de dados através de design de sistemas, proteção de dados através do desenvolvimento e uso de tecnologia, precauções organizacionais e procedimentais, funções ampliadas das autoridades responsáveis pela proteção de dados ou mecanismos de garantia da qualidade, como, por exemplo, auditorias de proteção de dados. Há, além disso, uma variedade de direitos de indivíduos afetados de tomar conhecimento, de obter informações, participar e exercer influência. $O$ fato de que a legislação da proteção de dados inclui um grande número de elementos constitutivos é, em geral, reconhecido atualmente. Mas, até o presente, elementos de origens diferentes têm tendido a existir lado a lado. No futuro, eles precisam ser tornados compativeis e ser entrelaçados apropriadamente. Essa é uma tarefa ambiciosa. Além disso, os próprios elementos constitutivos são complexos e exigem instrumentos altamente variados. Isso pode ser exemplificado pela proteção de dados através do design de sistemas, pela proteção de dados através da tecnologia e pelos direitos individuais à informação.

A proteção de dados através do design de sistemas refere-se a um nível que precede a regulamentação dos passos do processamento de dados. Resumindo amplas discussões, ela pode ser descrita como "a funcionalidade da proteção de dados incorporada em sistemas e procedimentos". ${ }^{64} \mathrm{~A}$ ideia principal é que a regulamentação dos passos do processamento de dados não é suficiente porque o processamento de dados tem lugar dentro de certos sistemas sociais, dentro de estruturas e procedimentos organizacionais e sob condições técnicas específicas. ${ }^{65}$ Esse contexto predeterminado influencia quais e quantos dados pessoais

64 KÖHNTOPP, Marit. Datenschutz technisch sichern. In: ROSSNAGEL, Alexander (Ed.). Allianz von Medienrecht und Informationstechnik? 2001, p. 55-56.

65 Veja também a seção 3.1 deste artigo. 
são necessários, por quanto tempo os dados têm de ser armazenados, quantas pessoas têm acesso a eles e quão transparente é o processamento de dados. Por conseguinte, a regulamentação e definição legal desse contexto antes do processamento subsequente de dados e informações não é menos importante do que a regulamentação das operações de processamento de dados. Isso deixa claro que "design de sistemas" não se refere apenas a sistemas ou procedimentos técnicos; as estruturas organizacionais ou os procedimentos de tomada de decisões também precisam ser levados em consideração. ${ }^{66}$ Portanto, a proteção de dados através do design de sistemas visa à formulação jurídica dos contextos social, organizacional, procedimental e técnico em que os dados e informações pessoais são tratados. Ela tem um escopo amplo, que vai da definição de competências administrativas para as quais as operações de processamento de dados estão orientadas, passando por abordagens organizacionais e procedimentais, até a instalação técnica de equipamentos de processamento de dados. Entendida dessa maneira, a proteção de dados através do design de sistemas é, evidentemente, uma tarefa ambiciosa a ser cumprida. Além disso, a realização da proteção de dados através do design de sistemas depende de uma elaboração - ainda não alcançada ${ }^{67}$ - clara e convincente dos objetivos da proteção e dos interesses tutelados. Em suma, o design de sistemas como elemento regulatório leva o direito referente à proteção de dados para além dos padrões tradicionais do direito regulatório.

Ao passo que os riscos sociais de sistemas de computação do tipo mainframe e as tecnologias de processamento de dados foram, no passado, a razão para desenvolver conceitos de proteção de dados, nesse meio tempo as tecnologias também são consideradas uma ferramenta para realizar a proteção de dados. As tecnologias amigáveis para com a privacidade ou que a incrementam desempenham um papel importante tanto no direito europeu quanto no nacional. Mas a proteção de dados através da tecnologia coloca exigências elevadas para o direito. O primeiro problema é que se tem de assegurar que a tecnologia com a qual os padrões normativos para o tratamento de informações e dados pessoais podem ser cumpridos esteja disponível. Os desenvolvimentos tecnológicos não podem ser objeto de um comando. É preciso recorrer a incentivos e mecanismos indiretos de exercer influência, por exemplo, dando apoio financeiro, institucionalizando órgãos ou procedimentos para desenvolver tecnologias amigáveis para com a privacidade ou emitindo selos de qualidade e certificados de produtos. Esses instrumentos do soft law poderiam influenciar o desenvolvimento da tecnologia, mas sua influência é limitada. Presumindo que tecnologias aplicáveis estejam disponíveis, a proteção

66 As elaborações acadêmicas são heterogêneas neste tocante.

67 Veja a seção 3.2 deste artigo. 
de dados através da moldagem da tecnologia define exigências para a seleção, o uso e a configuração de redes, sistemas, programas de processamento de dados ou meios de armazenamento. Antes das operações concretas de processamento, essas exigências visam assegurar que regras normativas já estejam tecnicamente estabelecidas ou possam ao menos ser cumpridas. A proteção de dados através da moldagem de tecnologia se justapõe à proteção de dados através do design de sistemas. Ela inclui, por exemplo, a exigência de configurações-padrão que sejam amigáveis em termos de proteção de dados. A proteção de dados através do uso de tecnologia compreende exigências das formas da tecnologia que acompanham e asseguram a regulamentação dos passos do processamento de dados, por exemplo, a obrigação de usar procedimentos criptográficos ao transmitir dados. Assim como a proteção de dados através do design de sistemas, a proteção de dados através do desenvolvimento, da moldagem e do uso de tecnologia é uma tarefa ambiciosa. E ela depende, da mesma maneira, de clareza a respeito dos objetivos da proteção e dos interesses protegidos, e, incluindo formas de soft law e instrumentos diversos, leva o direito referente à proteção de dados para além dos padrões tradicionais do direito regulatório.

Os direitos das pessoas afetadas à informação sobre a coleta e o uso de dados pessoais não parecem ser complicados, embora estejam direcionados para ações positivas por parte do Estado ou de pessoas privadas que processem dados pessoais. Entretanto, eles cumprem funções diferentes: visam transmitir aos sujeitos dos dados a informação de que estes necessitam a respeito do que outros sabem sobre eles para que possam se orientar em seu ambiente social. Abrem oportunidades para participar e influenciar os dados e o conhecimento. Salvaguardam a possibilidade de recursos judiciais. Devido a essas diferentes funções, eles precisam ser garantidos e implementados em diversos níveis e de várias formas: como informações gerais sobre tarefas e estruturas organizacionais de autoridades ou órgãos processadores de dados, como deveres de informação ou de notificação, ou como direitos a acesso a informações ou documentos. Além disso, o exercício de direitos à informação depende, na prática, de pré-requisitos sociais e individuais, que só podem ser influenciados indiretamente por meio do direito.

Concluindo com outro elemento regulatório que tem de ser aprofundado: a proteção de dados não pode ser garantida unicamente por mecanismos que concedam às pessoas afetadas proteção individual e mecanismos individuais de reparação. Também é preciso estabelecer mecanismos institucionais de garantias, ${ }^{68}$ de modo que se tem de decidir, por exemplo, sob que condições eles fazem

68 Com maior profundidade, MAYER-SCHÖNBERGER, Viktor. Beyond Privacy, beyond Rights - Toward a Systems Theory of Information Governance. Cal. L. Rev., v. 98, p. 1.853, 1.873 ss., 2010. 
sentido e como deveriam ser combinados com direitos individuais e recursos judiciais do sujeito de dados.

\subsubsection{Outras características do direito referente à proteção de dados}

Os conceitos para a regulamentação da proteção de dados se tornam complexos também devido ao fato de que a legislação de proteção de dados precisa ser articulada com normas legais pertinentes já existentes e que contêm, por exemplo, tarefas e competências em um campo particular. Uma articulação abrangente se faz necessária por causa das estreitas ligações existentes entre dados, informações, conhecimento e decisões. ${ }^{69}$ A proteção de dados não é um campo especial do direito que pudesse ficar isolado ao lado dos campos substantivos do direito. A proteção de dados diz respeito, antes, a uma dimensão fundamental e transversal. A necessidade de sua articulação com as disposições substantivas também aponta para a necessidade de diferenciar dentro do próprio direito referente à proteção de dados. É preciso considerar, por exemplo, as questões de quando regulamentações específicas para determinados setores são necessárias, quando regulamentações gerais é a opção mais adequada ou até que ponto uma legislação uniforme de proteção de dados para os âmbitos público e privado faz sentido.

Uma série de fatores adicionais torna conceitos apropriados para a regulamentação ainda mais desafiantes. Em contraposição aos conceitos originais de proteção de dados, de fato não é possível prever com facilidade o tratamento de dados e informações pessoais, o conhecimento gerado a partir deles e as decisões daí resultantes. A ideia de que esses processos pudessem ser quase completamente previstos, planejados e controlados por meios jurídicos ${ }^{70}$ mostrou ser demasiado simples. O processamento de dados e informações, a geração de informação e conhecimento, a tomada de decisões com base em informação e conhecimento incluem certa dinâmica e incerteza em muitos pontos. Isso se aplica com mais razão ainda com vistas ao uso de tecnologias. Consequentemente, é menos a ideia de controle que caracteriza ou deveria caracterizar o direito referente à proteção de dados do que, de modo semelhante ao direito ambiental, a ideia de regulamentação dos riscos. 
Como campo inovador e altamente dinâmico, o direito relativo à proteção de dados precisa ser, em termos de teoria jurídica, "direito reflexivo" e, de um ponto de vista doutrinal, uma mescla de estabilidade e dinâmica. Isso se reflete, por exemplo, na delegação de competências legislativas, no uso de termos jurídicos que são vagos e necessitam ser concretizados, em referências normativas a padrões técnicos dinamicamente adaptados, em regras que permitem experimentação, em procedimentos avaliativos ou em outras ferramentas para assegurar a capacidade de aprender e desenvolver-se.

Por último, mas não menos importante, o direito referente à proteção de dados não pode ser entendido sobre o pano de fundo das ideias tradicionais da implementação ou execução hierárquica das leis. Há uma série de abordagens teóricas gerais que visam suplantar conceitos de comando central por meio de conceitos mais flexíveis do direito. De um ponto de vista da ciência política, analisou-se como a substância da legislação da proteção de dados é tornada concreta pelas interações entre diferentes atores - os Poderes Legislativo, Executivo e Judiciário, órgãos responsáveis pela proteção de dados, usuários de dados, sujeitos de dados. ${ }^{71}$ Uma concepção normativa apropriada tem de ser responsiva à interação de atores que geram e concretizam o direito e manter, ao mesmo tempo, a perspectiva normativa. Em termos gerais, o direito relativo à proteção de dados mostra ser um campo do direito em que novas abordagens se fazem necessárias.

\section{Olhando para frente: 0 direito referente à proteção de dados como nova área central do direito}

Em suma, o direito referente à proteção de dados é uma área nova e altamente complexa do direito que ainda precisa de um considerável aprofundamento no tocante a seu assunto, aos interesses protegidos e aos conceitos apropriados para a regulamentação. Aprofundar a legislação também depende de percepções de outras disciplinas, por exemplo, das ciências sociais, das ciências tecnológicas ou da ciência da informação. Tudo isso faz com que estudar o direito relativo à proteção de dados seja tão empolgante.

71 Cf. BENNETT, Colin; RAAB, Charles. The Governance of Privacy, Aldershot: Ashgate, 2003; RAAB, Charles. The Governance of Data Protection. In: KOOIMAN, Jan (Ed.). Modern Governance. London: Sage, 1993, p. 89 ss. 
Abstract: This article proposes that data protection is by nature an extraordinarily complex field and therefore demands complex and multilevel regulation. Modern data protection requires new legal approaches and the article offers theoretical and legal analysis based on German and European law. The hypothesis is that elementary reasoning processes must be built in a different way in order to develop adequate data protection legislation, given the (i) complexity of the subject - from the point of view of data, information, knowledge and data and information flows, decisions and their respective consequences; (ii) complexity of the protected interests of the affected individuals and (iii) the complexity of the concepts that are appropriate for regulation.

Keywords: Personal data protection. Privacy. European Law.

Summary: 1 Introduction - $\mathbf{2}$ Guiding paradigms of data protection anchored on fundamental rights - $\mathbf{3}$ The complexity of data protection: analysis and consequences - $\mathbf{4}$ Looking ahead: personal data protection law as a new central legal field

Informação bibliográfica deste texto, conforme a NBR 6023:2002 da Associação Brasileira de Normas Técnicas (ABNT):

ALBERS, Marion. A complexidade da proteção de dados. Direitos Fundamentais \& Justiça, Belo Horizonte, ano 10, n. 35, p. 19-45, jul./dez. 2016. 